\title{
A New Hybrid Algorithm for Solving a System of Generalized Mixed Equilibrium Problems, Solving a Family of Quasi- $\phi$-Asymptotically Nonexpansive Mappings, and Obtaining Common Fixed Points in Banach Space
}

\author{
J. F. Tan and S. S. Chang \\ Department of Mathematics, Yibin University, Yibin, Sichuan 644007, China \\ Correspondence should be addressed to J. F. Tan, 15181109367@163.com \\ and S. S. Chang, changss@yahoo.cn \\ Received 14 February 2011; Accepted 14 April 2011 \\ Academic Editor: Vittorio Colao
}

Copyright (C) 2011 J. F. Tan and S. S. Chang. This is an open access article distributed under the Creative Commons Attribution License, which permits unrestricted use, distribution, and reproduction in any medium, provided the original work is properly cited.

The main purpose of this paper is to introduce a new hybrid iterative scheme for finding a common element of set of solutions for a system of generalized mixed equilibrium problems, set of common fixed points of a family of quasi- $\phi$-asymptotically nonexpansive mappings, and null spaces of finite family of $\gamma$-inverse strongly monotone mappings in a 2-uniformly convex and uniformly smooth real Banach space. The results presented in the paper improve and extend the corresponding results announced by some authors.

\section{Introduction}

Throughout this paper, we assume that $E$ is a real Banach space with a dual $E^{*}, C$ is a nonempty closed convex subset of $E$, and $\langle\cdot, \cdot\rangle$ is the duality pairing between members of $E$ and $E^{*}$. The mapping $J: E \rightarrow 2^{E^{*}}$ defined by

$$
J(x)=\left\{f^{*} \in E^{*}:\left\langle x, f^{*}\right\rangle=\|x\|^{2} ;\left\|f^{*}\right\|=\|x\|\right\}, \quad x \in E
$$

is called the normalized duality mapping.

Let $F: C \times C \rightarrow \mathbb{R}$ be a bifunction, let $B: C \rightarrow E^{*}$ be a nonlinear mapping, and let $\Phi: C \rightarrow \overline{\mathbb{R}}$ be a proper extended real-valued function. The "so-called" generalized mixed equilibrium problem for $F, B$, $\Phi$ is to find $x^{*} \in C$ such that

$$
F\left(x^{*}, y\right)+\left\langle y-x^{*}, B x^{*}\right\rangle+\Phi(y)-\Phi\left(x^{*}\right) \geq 0, \quad \forall y \in C .
$$


The set of solutions of (1.2) is denoted by $\operatorname{GMEP}(F, B, \Phi)$, that is,

$$
\operatorname{GMEP}(F, B, \Phi)=\left\{x \in C: F\left(x^{*}, y\right)+\left\langle y-x^{*}, B x^{*}\right\rangle+\Phi(y)-\Phi\left(x^{*}\right) \geq 0, \forall y \in C\right\}
$$

Special Examples

(1) If $\Phi \equiv 0$, then the problem (1.2) is reduced to the generalized equilibrium problem (GEP), and the set of its solutions is denoted by

$$
\operatorname{GEP}(F, B)=\left\{x \in C: F\left(x^{*}, y\right)+\left\langle y-x^{*}, B x^{*}\right\rangle \geq 0, \forall y \in C\right\} .
$$

(2) If $B \equiv 0$, then the problem (1.2) is reduced to the mixed equilibrium problem (MEP), and the set of its solutions is denoted by

$$
\operatorname{MEP}(F, B)=\left\{x \in C: F\left(x^{*}, y\right)+\Phi(y)-\Phi\left(x^{*}\right) \geq 0, \forall y \in C\right\}
$$

These show that the problem (1.2) is very general in the sense that numerous problems in physics, optimization, and economics reduce to finding a solution of (1.2). Recently, some methods have been proposed for the generalized mixed equilibrium problem in Banach space (see, e.g., [1-3]).

Let $E$ be a smooth, strictly convex, and reflexive Banach space, and let $C$ be a nonempty closed convex subset of $E$. Throughout this paper, the Lyapunov function $\phi: E \times E \rightarrow \mathbb{R}^{+}$is defined by

$$
\phi(x, y)=\|x\|^{2}-2\langle x, J y\rangle+\|y\|^{2}, \quad \forall x, y \in E .
$$

Following Alber [4], the generalized projection $\Pi_{C}: E \rightarrow C$ is defined by

$$
\Pi_{C}(x)=\underset{y \in C}{\arg \min } \phi(y, x), \quad \forall x \in E .
$$

Let $C$ be a nonempty closed convex subset of $E$, let $S: C \rightarrow C$ be a mapping, and let $F(S)$ be the set of fixed points of $S$. A point $p \in C$ is said to be an asymptotic fixed point of $T$ if there exists a sequence $\left\{x_{n}\right\} \subset C$ such that $x_{n} \rightarrow p$ and $\left\|x_{n}-S x_{n}\right\| \rightarrow 0$. We denoted the set of all asymptotic fixed points of $S$ by $\widetilde{F}(S)$. A point $p \in C$ is said to be a strong asymptotic fixed point of $S$ if there exists a sequence $\left\{x_{n}\right\} \subset C$ such that $x_{n} \rightarrow p$ and $\left\|x_{n}-S x_{n}\right\| \rightarrow 0$. We denoted the set of all strongly asymptotic fixed points of $S$ by $\widehat{F}(S)$.

A mapping $S: C \rightarrow C$ is said to be nonexpansive if

$$
\|S x-S y\| \leq\|x-y\|, \quad \forall x, y \in C
$$

A mapping $S: C \rightarrow C$ is said to be relatively nonexpansive [5] if $F(S) \neq \emptyset, F(S)=\tilde{F}(S)$ and

$$
\phi(p, S x) \leq \phi(p, x), \quad \forall x \in C, p \in F(S)
$$



$\widehat{F}(S)$ and

A mapping $S: C \rightarrow C$ is said to be weak relatively nonexpansive [6] if $F(S) \neq \emptyset, F(S)=$

$$
\phi(p, S x) \leq \phi(p, x), \quad \forall x \in C, p \in F(S)
$$

A mapping $S: C \rightarrow C$ is said to be closed if for any sequence $\left\{x_{n}\right\} \subset C$ with $x_{n} \rightarrow x$ and $S x_{n} \rightarrow y$, then $S x=y$.

A mapping $S: C \rightarrow C$ is said to be quasi- $\phi$-nonexpansive if $F(S) \neq \emptyset$ and

$$
\phi(p, S x) \leq \phi(p, x), \quad \forall x \in C, p \in F(S)
$$

A mapping $S: C \rightarrow C$ is said to be quasi- $\phi$-asymptotically nonexpansive, if $F(S) \neq \emptyset$ and there exists a real sequence $\left\{k_{n}\right\} \subset[1, \infty)$ with $k_{n} \rightarrow 1$ such that

$$
\phi\left(p, S^{n} x\right) \leq k_{n} \phi(p, x), \quad \forall n \geq 1, x \in C, p \in F(S) .
$$

From the definition, it is easy to know that each relatively nonexpansive mapping is closed. The class of quasi- $\phi$-asymptotically nonexpansive mappings contains properly the class of quasi- $\phi$-nonexpansive mappings as a subclass. The class of quasi- $\phi$-nonexpansive mappings contains properly the class of weak relatively nonexpansive mappings as a subclass, and the class of weak relatively nonexpansive mappings contains properly the class of relatively nonexpansive mappings as a subclass, but the converse may be not true.

A mapping $A: C \rightarrow E^{*}$ is said to be $\alpha$-inverse strongly monotone if there exists $\alpha>0$ such that

$$
\langle x-y, A x-A y\rangle \geq \alpha\|A x-A y\|^{2} .
$$

If $A$ is an $\alpha$-inverse strongly monotone mapping, then it is $1 / \alpha$-Lipschitzian.

Iterative approximation of fixed points for relatively nonexpansive mappings in the setting of Banach spaces has been studied extensively by many authors. In 2005, Matsushita and Takahashi [5] obtained weak and strong convergence theorems to approximate a fixed point of a single relatively nonexpansive mapping. Recently, Su et al. [6, 7], Zegeye and Shahzad [8], Wattanawitoon and Kumam [9], and Zhang [10] extend the notion from relatively nonexpansive mappings or quasi- $\phi$-nonexpansive mappings to quasi$\phi$-asymptotically nonexpansive mappings and also prove some convergence theorems to approximate a common fixed point of quasi- $\phi$-nonexpansive mappings or quasi- $\phi$ asymptotically nonexpansive mappings.

Motivated and inspired by these facts, the purpose of this paper is to introduce a hybrid iterative scheme for finding a common element of null spaces of finite family of inverse strongly monotone mappings, set of common fixed points of an infinite family of quasi- $\phi$-asymptotically nonexpansive mappings, and the set of solutions of generalized mixed equilibrium problem. 


\section{Preliminaries}

For the sake of convenience, we first recall some definitions and conclusions which will be needed in proving our main results.

A Banach space $E$ is said to be strictly convex if $\|x+y\| / 2<1$ for all $x, y \in U=\{z \in$ $E:\|z\|=1\}$ with $x \neq y$. It is said to be uniformly convex if for each $\epsilon \in(0,2]$, there exists $\delta>0$ such that $\|x+y\| / 2 \leq 1-\delta$ for all $x, y \in U$ with $\|x-y\| \geq \epsilon$. The convexity modulus of $E$ is the function $\delta_{E}:(0,2] \rightarrow[0,1]$ defined by

$$
\delta_{E}(\epsilon)=\inf \left\{1-\left\|\frac{1}{2}(x+y)\right\|: x, y \in U,\|x-y\| \geq \epsilon\right\},
$$

for all $\epsilon \in(0,2]$. It is well known that $\delta_{E}(\epsilon)$ is a strictly increasing and continuous function with $\delta_{E}(0)=0$, and $\delta_{E}(\epsilon) / \epsilon$ is nondecreasing for all $\epsilon \in(0,2]$. Let $p>1$, then $E$ is said to be $p$-uniformly convex if there exists a constant $c>0$ such that $\delta_{E}(\epsilon) \geq c \epsilon^{p}$, for all $\epsilon \in(0,2]$. The space $E$ is said to be smooth if the limit

$$
\lim _{t \rightarrow 0} \frac{\|x+t y\|-\|x\|}{t}
$$

exists for all $x, y \in U$. And $E$ is said to be uniformly smooth if the limit exists uniformly in $x, y \in U$.

In the sequel, we will make use of the following lemmas.

Lemma 2.1 (see [11]). Let $E$ be a 2-uniformly convex real Banach space, then for all $x, y \in E$, the inequality $\|x-y\| \leq\left(2 / c^{2}\right)\|J x-J y\|$ holds, where $0<c \leq 1$, and $c$ is called the 2-uniformly convex constant of $E$.

Lemma 2.2 (see [12]). Let $E$ be a smooth, strict convex, and reflexive Banach space, and let $C$ be a nonempty closed convex subset of $E$, then the following conclusions hold:

(i) $\phi\left(x, \Pi_{C} y\right)+\phi\left(\Pi_{C} y, y\right) \leq \phi(x, y)$, for all $x \in C, y \in E$,

(ii) let $x \in E$ and $z \in C$, then

$$
z=\Pi_{C} x \Longleftrightarrow\langle z-y, J x-J z\rangle \geq 0, \quad \forall y \in C .
$$

Lemma 2.3 (see [12]). Let E be a uniformly convex and smooth Banach space, and let $\left\{x_{n}\right\},\left\{y_{n}\right\}$ be sequences of $E$. If $\phi\left(x_{n}, y_{n}\right) \rightarrow 0($ as $n \rightarrow \infty)$ and either $\left\{x_{n}\right\}$ or $\left\{y_{n}\right\}$ is bounded, then $x_{n}-y_{n} \rightarrow$ $0($ as $n \rightarrow \infty)$.

Lemma 2.4 (see [10]). Let $E$ be a uniformly convex Banach space, let $r$ be a positive number, and let $B_{r}(0)$ be a closed ball of $E$. For any given points $\left\{x_{1}, x_{2}, \ldots, x_{n}, \ldots\right\} \subset B_{r}(0)$ and for any given positive numbers $\left\{\lambda_{1}, \lambda_{2}, \ldots\right\}$ with $\sum_{n=1}^{\infty} \lambda_{n}=1$, there exists a continuous, strictly increasing, and convex function $g:[0,2 r) \rightarrow[0, \infty)$ with $g(0)=0$ such that for any $i, j \in\{1,2, \ldots\}, i<j$,

$$
\left\|\sum_{n=1}^{\infty} \lambda_{n} x_{n}\right\|^{2} \leq \sum_{n=1}^{\infty} \lambda_{n}\left\|x_{n}\right\|^{2}-\lambda_{i} \lambda_{j} g\left(\left\|x_{i}-x_{j}\right\|\right) .
$$


For solving the generalized mixed equilibrium problem, let us assume that the bifunction $F: C \times C \rightarrow \mathbb{R}$ satisfies the following conditions:

(A1) $F(x, x)=0$ for all $x \in C$,

(A2) $F$ is monotone, that is, $F(x, y)+F(y, x) \leq 0$, for all $x, y \in C$,

(A3) $\lim \sup _{t \downarrow 0} F(x+t(z-x), y) \leq F(x, y)$, for all $x, y, z \in C$,

(A4) the function $y \mapsto F(x, y)$ is convex and lower semicontinuous.

Lemma 2.5 (see [13]). Let $E$ be a smooth, strict convex, and reflexive Banach space, and let $C$ be a nonempty closed convex subset of $E$. Let $F: C \times C \rightarrow \mathbb{R}$ be a bifunction satisfying conditions (A1)-(A4). Let $r>0$ and $x \in E$, then there exists $z \in C$ such that

$$
F(z, y)+\frac{1}{r}\langle y-z, J z-J x\rangle \geq 0, \quad \forall y \in C
$$

By the same way as given in the proofs of [14, Lemmas 2.8 and 2.9], we can prove that the bifunction

$$
\Gamma(x, y)=F(x, y)+\Phi(y)-\Phi(x)+\langle y-x, B x\rangle, \quad \forall x, y \in C
$$

satisfies conditions (A1)-(A4) and the following conclusion holds.

Lemma 2.6. Let $E$ be a smooth, strictly convex, and reflexive Banach space, and let $C$ be a nonempty closed convex subset of $E$. Let $F: C \times C \rightarrow \mathbb{R}$ be a bifunction satisfying conditions (A1)-(A4), let $B$ : $C \rightarrow E^{*}$ be a $\beta$-inverse strongly monotone mapping, and let $\Phi: C \rightarrow \mathbb{R}$ be a lower semicontinuous and convex function. For given $r>0$ and $x \in E$, define a mapping $K_{r}^{\Gamma}: E \rightarrow C$ by

$$
K_{r}^{\Gamma}(x)=\left\{z \in C: F(z, y)+\Phi(y)-\Phi(z)+\langle y-z, B z\rangle+\frac{1}{r}\langle y-z, J z-J x\rangle \geq 0, \forall y \in C\right\},
$$

then the following hold:

(i) $K_{r}^{\Gamma}$ is single valued,

(ii) $K_{r}^{\Gamma}$ is a firmly nonexpansive-type mapping, that is, for all $x, y, \in E$,

$$
\left\langle K_{r}^{\Gamma}(x)-K_{r}^{\Gamma}(y), J K_{r}^{\Gamma}(x)-J K_{r}^{\Gamma}(y)\right\rangle \leq\left\langle K_{r}^{\Gamma}(x)-K_{r}^{\Gamma}(y), J x-J y\right\rangle,
$$

(iii) $F\left(K_{r}^{\Gamma}\right)=\operatorname{GMEP}(F, \Phi, B)$,

(iv) $\operatorname{GMEP}(F, \Phi, B)$ is closed and convex,

(v) $\phi\left(p, K_{r}^{\Gamma}(x)\right)+\phi\left(K_{r}^{\Gamma}(x), x\right) \leq \phi(p, x)$, for all $p \in F\left(K_{r}^{\Gamma}\right)$.

In the sequel, we make use of the function $V: E \times E^{*} \rightarrow \mathbb{R}$ defined by

$$
V\left(x, x^{*}\right)=\|x\|^{2}-2\left\langle x, x^{*}\right\rangle+\left\|x^{*}\right\|^{2},
$$

for all $x \in E$ and $x^{*} \in E^{*}$. Observe that $V\left(x, x^{*}\right)=\phi\left(x, J^{-1} x^{*}\right)$ for all $x \in E$ and $x^{*} \in E^{*}$. The following lemma is well known. 
Lemma 2.7 (see [4]). Let $E$ be a smooth, strict convex, and reflexive Banach space with $E^{*}$ as its dual, then

$$
V\left(x, x^{*}\right)+2\left\langle J^{-1} x^{*}-x, y^{*}\right\rangle \leq V\left(x, x^{*}+y^{*}\right),
$$

for all $x \in E$ and $x^{*}, y^{*} \in E^{*}$.

\section{Main Results}

In this section, we will propose the following new iterative scheme $\left\{x_{n}\right\}$ for finding a common element of set of solutions for a system of generalized mixed equilibrium problems, the set of common fixed points of a family of quasi- $\phi$-asymptotically nonexpansive mappings, and null spaces of finite family of $\gamma$-inverse strongly monotone mappings in the setting of 2-uniformly convex and uniformly smooth real Banach spaces:

$$
\begin{gathered}
x_{0} \in C_{0}=C, \\
y_{n}=\Pi_{C} J^{-1}\left(J x_{n}-\lambda A_{n+1} x_{n}\right), \\
z_{n}=J^{-1}\left(\alpha_{n, 0} J x_{n}+\sum_{i=1}^{\infty} \alpha_{n, i} J T_{i}^{n} y_{n}\right), \\
u_{n}=K_{r_{M, n}}^{\Gamma_{M}} K_{r_{M-1, n}}^{\Gamma_{M-1}} \cdots K_{r_{2, n}}^{\Gamma_{2}} K_{r_{1, n}}^{\Gamma_{1}} z_{n}, \\
C_{n+1}=\left\{v \in C_{n}: \phi\left(v, u_{n}\right) \leq \phi\left(v, x_{n}\right)+\xi_{n}\right\}, \\
x_{n+1}=\prod_{C_{n+1}} x_{0}, \quad n \geq 0,
\end{gathered}
$$

where $K_{r_{k, n}}^{\Gamma_{k}}: C \rightarrow C, k=1,2, \ldots, M$ is the mapping defined by $(2.7), A_{n}=A_{n(\bmod N)}, r_{k, n} \in$ $[d, \infty)$ for some $d>0$ and $0<\lambda<c^{2} \gamma / 2$, where $c$ is the 2-uniformly convex constant of $E$, for each $n \geq 1, \alpha_{n, 0}+\sum_{i=1}^{\infty} \alpha_{n, i}=1$ and for each $j \geq 1, \liminf _{n \rightarrow \infty} \alpha_{n, 0} \alpha_{n, j}>0$.

Definition 3.1. A countable family of mappings $\left\{T_{i}: C \rightarrow C\right\}$ is said to be uniformly quasi$\varphi$-asymptotically nonexpansive mappings if there exists a sequence $\left\{k_{n}\right\} \subset[1, \infty)$ with $k_{n} \rightarrow 1$ such that for each $i \geq 1$

$$
\left\|T_{i}^{n} x-T_{i}^{n} y\right\| \leq k_{n}\|x-y\|, \quad \forall x, y \in C, \text { and for each } n \geq 1
$$

Theorem 3.2. Let $C$ be a nonempty closed and convex subset of a 2-uniformly convex and uniformly smooth real Banach space $E$ with a dual $E^{*}$. Let $\left\{T_{i}: C \rightarrow C\right\}_{i=1}^{\infty}$ be a countable family of closed and uniformly quasi- $\varphi$-asymptotically nonexpansive mappings with a sequence $\left\{k_{n}\right\} \subset[1, \infty)$ such that $k_{n} \rightarrow 1$. Suppose further that for each $i \geq 1, T_{i}$ is uniformly $L_{i}$-Lipschitzian. Let $A_{n}: C \rightarrow E^{*}$, $n=1,2, \ldots, N$ be a finite family of $\gamma_{n}$-inverse strongly monotone mappings, and let $\gamma=\min \left\{\gamma_{n}, n=\right.$ $1,2, \ldots, N\}$. Let $\left\{F_{m}: C \times C \rightarrow \mathbb{R}, m=1,2, \ldots, M\right\}$ be a finite family of equilibrium functions satisfying conditions (A1)-(A4), and $\left\{\Phi_{m}: C \rightarrow \mathbb{R}, m=1,2, \ldots, M\right\}$ be a finite family of lower 
semicontinuous convex function, and let $\left\{B_{m}: C \rightarrow E^{*}, m=1,2, \ldots, M\right\}$ be a finite family of $\beta_{m}$-inverse strongly monotone mappings. If

$$
\Omega=\bigcap_{i=1}^{\infty} F\left(T_{i}\right) \cap \bigcap_{n=1}^{N} A_{n}^{-1}(0) \cap \bigcap_{m=1}^{M} \operatorname{GMEP}\left(F_{m}, B_{m}, \Phi_{m}\right)
$$

is a nonempty and bounded subset in $C$ and $\xi_{n}=\sup _{p \in \Omega}\left(k_{n}-1\right) \phi\left(p, x_{n}\right)$, then the sequence $\left\{x_{n}\right\}$ defined by (3.1) converges strongly to some point $x^{*} \in \Omega$.

Proof. We divide the proof of Theorem 3.2 into five steps.

(I) Sequences $\left\{x_{n}\right\},\left\{y_{n}\right\}$, and $\left\{T_{i}^{n} y_{n}\right\}$ all are bounded.

In fact, since $x_{n}=\Pi_{C_{n}} x_{0}$, for any $p \in \Omega$, from Lemma 2.2, we have

$$
\phi\left(x_{n}, x_{0}\right)=\phi\left(\Pi_{C_{n}} x_{0}, x_{0}\right) \leq \phi\left(p, x_{0}\right)-\phi\left(p, x_{n}\right) \leq \phi\left(p, x_{0}\right)
$$

This implies that the sequence $\left\{\phi\left(x_{n}, x_{0}\right)\right\}$ is bounded, and so $\left\{x_{n}\right\}$ is bounded.

On the other hand, by Lemmas 2.1 and 2.7 , we have that

$$
\begin{aligned}
\phi\left(p, y_{n}\right)= & \phi\left(p, \Pi_{C} J^{-1}\left(J x_{n}-\lambda A_{n+1} x_{n}\right)\right) \\
\leq & \phi\left(p, J^{-1}\left(J x_{n}-\lambda A_{n+1} x_{n}\right)\right) \\
= & V\left(p, J x_{n}-\lambda A_{n+1} x_{n}\right) \\
\leq & V\left(p,\left(J x_{n}-\lambda A_{n+1} x_{n}\right)+\lambda A_{n+1} x_{n}\right)-2\left\langle J^{-1}\left(J x_{n}-\lambda A_{n+1} x_{n}\right)-p, \lambda A_{n+1} x_{n}\right\rangle \\
= & V\left(p, J x_{n}\right)-2 \lambda\left\langle J^{-1}\left(J x_{n}-\lambda A_{n+1} x_{n}\right)-p, A_{n+1} x_{n}\right\rangle \\
= & \phi\left(p, x_{n}\right)-2 \lambda\left\langle x_{n}-p, A_{n+1} x_{n}\right\rangle-2 \lambda\left\langle J^{-1}\left(J x_{n}-\lambda A_{n+1} x_{n}\right)-x_{n}, A_{n+1} x_{n}\right\rangle \\
= & \phi\left(p, x_{n}\right)-2 \lambda\left\langle x_{n}-p, A_{n+1} x_{n}-A_{n+1} p\right\rangle \quad\left(\text { since } A_{n} p=0, \forall n \geq 1\right) \\
& -2 \lambda\left\langle J^{-1}\left(J x_{n}-\lambda A_{n+1} x_{n}\right)-x_{n}, A_{n+1} x_{n}\right\rangle \\
\leq & \phi\left(p, x_{n}\right)-2 \lambda \gamma\left\|A_{n+1} x_{n}\right\|^{2}+2 \lambda\left\|J^{-1}\left(J x_{n}-\lambda A_{n+1} x_{n}\right)-J^{-1} J x_{n}\right\| \times\left\|A_{n+1} x_{n}\right\| \\
\leq & \phi\left(p, x_{n}\right)-2 \lambda \gamma\left\|A_{n+1} x_{n}\right\|^{2}+\frac{4 \lambda^{2}}{c^{2}}\left\|A_{n+1} x_{n}\right\|^{2} \quad(\text { by Lemma 2.1) } \\
\leq & \phi\left(p, x_{n}\right)+2 \lambda\left(\frac{2 \lambda}{c^{2}}-\gamma\right)\left\|A_{n+1} x_{n}\right\|^{2} .
\end{aligned}
$$


Thus, using the fact that $\lambda \leq\left(c^{2} / 2\right) \gamma$, we have that

$$
\phi\left(p, y_{n}\right) \leq \phi\left(p, x_{n}\right)
$$

Moreover, by the assumption that $\left\{T_{i}: C \rightarrow C\right\}_{i=1}^{\infty}$ is a countable family of uniformly quasi$\varphi$-asymptotically nonexpansive mappings with a sequence $\left\{k_{n, i}\right\} \subset[1, \infty)$ such that $k_{n}=$ $\sup _{i \geq 1} k_{n, i} \rightarrow 1(n \rightarrow \infty)$, hence for any given $p \in \Omega$, from (3.6) we have that

$$
\varphi\left(p, T_{i}^{n} y_{n}\right) \leq k_{n} \varphi\left(p, y_{n}\right) \leq k_{n} \varphi\left(p, x_{n}\right), \quad \forall n \geq 1, i \geq 1
$$

Hence, for each $i \geq 1,\left\{T_{i}^{n} y_{n}\right\}$ is also bounded, denoted by

$$
M=\sup _{n \geq 0, i \geq 1}\left\{\left\|x_{n}\right\|,\left\|y_{n}\right\|,\left\|T_{i}^{n} y_{n}\right\|\right\}<\infty
$$

By the way, from the definition of $\left\{\xi_{n}\right\}$, it is easy to see that

$$
\xi_{n}=\sup _{p \in \Omega}\left(k_{n}-1\right) \phi\left(p, x_{n}\right) \leq \sup _{p \in \Omega}\left(k_{n}-1\right)(\|p\|+M)^{2} \longrightarrow 0 \quad(n \longrightarrow \infty) .
$$

(II) For each $n \geq 0, C_{n}$ is a closed and convex subset of $C$ and $\Omega \subset C_{n}$.

It is obvious that $C_{0}=C$ is closed and convex. Suppose that $C_{n}$ is closed and convex for some $n \geq 1$. Since the inequality $\phi\left(v, u_{n}\right) \leq \phi\left(v, x_{n}\right)+\xi_{n}$ is equivalent to

$$
2\left\langle v, J x_{n}-J u_{n}\right\rangle \leq\left\|x_{n}\right\|^{2}-\left\|u_{n}\right\|^{2}+\xi_{n}
$$

therefore, we have

$$
C_{n+1}=\left\{v \in C_{n}: 2\left\langle v, J x_{n}-J u_{n}\right\rangle \leq\left\|x_{n}\right\|^{2}-\left\|u_{n}\right\|^{2}+\xi_{n}\right\}
$$

This implies that $C_{n+1}$ is closed and convex. Thus, for each $n \geq 0, C_{n}$ is a closed and convex subset of $C$. 
Next, we prove that $\Omega \subset C_{n}$ for all $n \geq 0$. Indeed, it is obvious that $\Omega \subset C_{0}=C$. Suppose that $\Omega \subset C_{n}$ for some $n \geq 1$. Since $E$ is uniformly smooth, $E^{*}$ is uniformly convex. For any given $p \in \Omega \subset C_{n}$ and for any positive integer $j>0$, from Lemma 2.4, we have

$$
\begin{aligned}
\phi\left(p, u_{n}\right)= & \phi\left(p, K_{r_{M, n}}^{\Gamma_{M}} K_{r_{M-1, n}}^{\Gamma_{M-1}} \cdots K_{r_{2, n}}^{\Gamma_{2}} K_{r_{1, n}}^{\Gamma_{1}} z_{n}\right) \\
\leq & \phi\left(p, z_{n}\right)=\phi\left(p, J^{-1}\left(\alpha_{n, 0} J x_{n}+\sum_{i=1}^{\infty} \alpha_{n, i} J T_{i}^{n} y_{n}\right)\right) \\
= & \|p\|^{2}-2\left\langle p, \alpha_{n, 0} J x_{n}+\sum_{i=1}^{\infty} \alpha_{n, i} J T_{i}^{n} y_{n}\right\rangle+\left\|\alpha_{n, 0} J x_{n}+\sum_{i=1}^{\infty} \alpha_{n, i} J T_{i}^{n} y_{n}\right\|^{2} \\
\leq & \|p\|^{2}-2 \alpha_{n, 0}\left\langle p, J x_{n}\right\rangle-2 \sum_{i=1}^{\infty} \alpha_{n, i}\left\langle p, J T_{i}^{n} y_{n}\right\rangle \\
& +\alpha_{n, 0}\left\|x_{n}\right\|^{2}+\sum_{i=1}^{\infty} \alpha_{n, i}\left\|T_{i}^{n} y_{n}\right\|^{2}-\alpha_{n, 0} \alpha_{n, j} g\left(\left\|J x_{n}-J T_{j}^{n} y_{n}\right\|\right) \\
= & \alpha_{n, 0} \phi\left(p, x_{n}\right)+\sum_{i=1}^{\infty} \alpha_{n, i} \phi\left(p, T_{i}^{n} y_{n}\right)-\alpha_{n, 0} \alpha_{n, j} g\left(\left\|J x_{n}-J T_{j}^{n} y_{n}\right\|\right) \\
\leq & \alpha_{n, 0} \phi\left(p, x_{n}\right)+\sum_{i=1}^{\infty} \alpha_{n, i} k_{n} \phi\left(p, y_{n}\right)-\alpha_{n, 0} \alpha_{n, j} g\left(\left\|J x_{n}-J T_{j}^{n} y_{n}\right\|\right) .
\end{aligned}
$$

Having this together with (3.6), we have

$$
\begin{aligned}
\phi\left(p, u_{n}\right) & \leq \phi\left(p, z_{n}\right) \\
& \leq \alpha_{n, 0} \phi\left(p, x_{n}\right)+\sum_{i=1}^{\infty} \alpha_{n, i} k_{n} \phi\left(p, x_{n}\right)-\alpha_{n, 0} \alpha_{n, j} g\left(\left\|J x_{n}-J T_{j}^{n} y_{n}\right\|\right) \\
& \leq k_{n} \phi\left(p, x_{n}\right)-\alpha_{n, 0} \alpha_{n, j} g\left(\left\|J x_{n}-J T_{j}^{n} y_{n}\right\|\right) \\
& \leq \phi\left(p, x_{n}\right)+\sup _{z \in \Omega}\left(k_{n}-1\right) \phi\left(z, x_{n}\right)-\alpha_{n, 0} \alpha_{n, j} g\left(\left\|J x_{n}-J T_{j}^{n} y_{n}\right\|\right) \\
& =\phi\left(p, x_{n}\right)+\xi_{n}-\alpha_{n, 0} \alpha_{n, j} g\left(\left\|J x_{n}-J T_{j}^{n} y_{n}\right\|\right) \\
& \leq \phi\left(p, x_{n}\right)+\xi_{n} .
\end{aligned}
$$

Hence, $p \in C_{n+1}$ and $\Omega \subset C_{n}$ for all $n \geq 0$.

(III) $\left\{x_{n}\right\}$ is a Cauchy sequence.

Since $x_{n}=\prod_{C_{n}} x_{0}$ and $x_{n+1}=\prod_{C_{n+1}} x_{0} \in C_{n+1} \subset C_{n}$, we have that

$$
\phi\left(x_{n}, x_{0}\right) \leq \phi\left(x_{n+1}, x_{0}\right),
$$


which implies that the sequence $\left\{\phi\left(x_{n}, x_{0}\right)\right\}$ is nondecreasing and bounded, and so $\lim _{n \rightarrow \infty} \phi\left(x_{n}, x_{0}\right)$ exists. Hence, for any positive integer $m$, using Lemma 2.2 we have

$$
\phi\left(x_{n+m}, x_{n}\right)=\phi\left(x_{n+m}, \Pi_{C_{n}} x_{0}\right) \leq \phi\left(x_{n+m}, x_{0}\right)-\phi\left(x_{n}, x_{0}\right),
$$

for all $n \geq 0$. Since $\lim _{n \rightarrow \infty} \phi\left(x_{n}, x_{0}\right)$ exists, we obtain that

$$
\phi\left(x_{n+m}, x_{n}\right) \longrightarrow 0 \quad(n \longrightarrow \infty), \forall m \in Z^{+}
$$

Thus, by Lemma 2.3, we have that $\left\|x_{n+m}-x_{n}\right\| \rightarrow 0$ as $n \rightarrow \infty$. This implies that the sequence $\left\{x_{n}\right\}$ is a Cauchy sequence in $C$. Since $C$ is a nonempty closed subset of Banach space $E$, it is complete. Hence, there exists an $x^{*}$ in $C$ such that

$$
x_{n} \longrightarrow x^{*} \quad(n \longrightarrow \infty)
$$

(IV) We show that $x^{*} \in \bigcap_{i=1}^{\infty} F\left(T_{i}\right)$.

Since $x_{n+1} \in C_{n+1}$ by the structure of $C_{n+1}$, we have that

$$
\phi\left(x_{n+1}, u_{n}\right) \leq \phi\left(x_{n+1}, x_{n}\right)+\xi_{n}
$$

Again by (3.16) and Lemma 2.3, we get that $\lim _{n \rightarrow \infty}\left\|x_{n+1}-u_{n}\right\|=0$. But

$$
\left\|x_{n}-u_{n}\right\| \leq\left\|x_{n}-x_{n+1}\right\|+\left\|x_{n+1}-u_{n}\right\|
$$

Thus,

$$
\lim _{n \rightarrow \infty}\left\|x_{n}-u_{n}\right\|=0
$$

This implies that $u_{n} \rightarrow x^{*}$ as $n \rightarrow \infty$. Since $J$ is norm-to-norm uniformly continuous on bounded subsets of $E$, we have that

$$
\lim _{n \rightarrow \infty}\left\|J x_{n}-J u_{n}\right\|=0
$$

From (3.13), (3.20), and (3.21), we have that

$$
\begin{aligned}
\alpha_{n, 0} \alpha_{n, j} g\left(\left\|J x_{n}-J T_{j}^{n} y_{n}\right\|\right) & \leq \phi\left(p, x_{n}\right)-\phi\left(p, u_{n}\right)+\xi_{n} \\
& =\left\|x_{n}\right\|^{2}-\left\|u_{n}\right\|^{2}+2\left\langle p, J u_{n}-J x_{n}\right\rangle+\xi_{n} \\
& \leq\left\|x_{n}-u_{n}\right\|\left(\left\|u_{n}\right\|+\left\|x_{n}\right\|\right)+2\left\langle p, J u_{n}-J x_{n}\right\rangle+\xi_{n} \longrightarrow 0 \quad(n \longrightarrow \infty) .
\end{aligned}
$$


International Journal of Mathematics and Mathematical Sciences

In view of condition $\lim _{\inf }{ }_{n \rightarrow \infty} \alpha_{n, 0} \alpha_{n, j}>0$, we see that

$$
g\left(\left\|J x_{n}-J T_{j}^{n} y_{n}\right\|\right) \longrightarrow 0 \quad(n \longrightarrow \infty)
$$

It follows from the property of $g$ that

$$
\left\|J x_{n}-J T_{j}^{n} y_{n}\right\| \longrightarrow 0 \quad(n \longrightarrow \infty)
$$

Since $x_{n} \rightarrow x^{*}$ and $J$ is uniformly continuous, it yields $J x_{n} \rightarrow J x^{*}$. Hence, from (3.24), we have

$$
J T_{j}^{n} y_{n} \longrightarrow J x^{*} \quad(n \longrightarrow \infty)
$$

Since $E^{*}$ is uniformly smooth and $J^{-1}$ is uniformly continuous, it follows that

$$
T_{j}^{n} y_{n} \longrightarrow x^{*} \quad(n \longrightarrow \infty), \forall j \geq 1
$$

Moreover, using inequalities (3.12) and (3.5), we obtain that

$$
\begin{aligned}
\phi\left(p, u_{n}\right) & \leq \alpha_{n, 0} \phi\left(p, x_{n}\right)+\sum_{i=1}^{\infty} \alpha_{n, i} k_{n} \phi\left(p, x_{n}\right)+\sum_{i=1}^{\infty} \alpha_{n, i} k_{n} 2 \lambda\left(\frac{2}{c^{2}} \lambda-\gamma\right)\left\|A_{n+1} x_{n}\right\|^{2} \\
& \leq \phi\left(p, x_{n}\right)+\xi_{n}+k_{n} 2 \lambda\left(\frac{2}{c^{2}} \lambda-\gamma\right)\left\|A_{n+1} x_{n}\right\|^{2}, \quad \forall p \in \Omega .
\end{aligned}
$$

This implies that

$$
k_{n} 2 \lambda\left(\gamma-\frac{2}{c^{2}} \lambda\right)\left\|A_{n+1} x_{n}\right\|^{2} \leq \phi\left(p, x_{n}\right)-\phi\left(p, u_{n}\right)+\xi_{n},
$$

that is,

$$
\lim _{n \rightarrow \infty}\left\|A_{n+1} x_{n}\right\|^{2}=0
$$

It follows from (3.1) and (3.29) that we have

$$
\begin{aligned}
\lim _{n \rightarrow \infty}\left\|y_{n}-x^{*}\right\| & =\lim _{n \rightarrow \infty}\left\|\Pi_{C} J^{-1}\left(J x_{n}-\lambda A_{n+1} x_{n}\right)-x^{*}\right\| \\
& \leq \lim _{n \rightarrow \infty}\left\|J^{-1}\left(J x_{n}-\lambda A_{n+1} x_{n}\right)-x^{*}\right\|=0 .
\end{aligned}
$$


Furthermore, by the assumption that for each $j \geq 1, T_{j}$ is uniformly $L_{i}$-Lipschitz continuous, hence, we have

$$
\begin{aligned}
\left\|T_{j}^{n+1} y_{n}-T_{j}^{n} y_{n}\right\| & \leq\left\|T_{j}^{n+1} y_{n}-T_{j}^{n+1} y_{n+1}\right\|+\left\|T_{j}^{n+1} y_{n+1}-y_{n+1}\right\|+\left\|y_{n+1}-y_{n}\right\|+\left\|y_{n}-T_{j}^{n} y_{n}\right\| \\
& \leq\left(L_{j}+1\right)\left\|y_{n+1}-y_{n}\right\|+\left\|T_{j}^{n+1} y_{n+1}-y_{n+1}\right\|+\left\|y_{n}-T_{j}^{n} y_{n}\right\| .
\end{aligned}
$$

This together with (3.26) and (3.30) yields

$$
\lim _{n \rightarrow \infty}\left\|T_{j}^{n+1} y_{n}-T_{j}^{n} y_{n}\right\|=0
$$

Hence, from (3.26), we have

$$
\lim _{n \rightarrow \infty} T_{j}^{n+1} y_{n}=x^{*}
$$

that is,

$$
\lim _{n \rightarrow \infty} T_{j} T_{j}^{n} y_{n}=x^{*}
$$

In view of (3.26) and the closeness of $T_{j}$, it yields that $T_{j} x^{*}=x^{*}$ for all $j \geq 1$. This implies that $x^{*} \in \bigcap_{j=1}^{\infty} F\left(T_{j}\right)$.

(IV) Now, we prove that $x^{*} \in \bigcap_{n=1}^{N} A_{n}^{-1}(0)$.

It follows from (3.29) that

$$
\lim _{n \rightarrow \infty}\left\|A_{n+1} x_{n}\right\|=0
$$

Since $\lim _{n \rightarrow \infty} x_{n}=x^{*}$, we have that for every subsequence $\left\{x_{n_{j}}\right\}_{j \geq 1}$ of $\left\{x_{n}\right\}_{n \geq 0}, \lim _{j \rightarrow \infty} x_{n_{j}}=x^{*}$ and

$$
\lim _{j \rightarrow \infty} A_{n_{j}+1} x_{n_{j}}=0
$$

Let $\left\{n_{q}\right\}_{q \geq 1} \subset \mathbb{N}$ be an increasing sequence of natural numbers such that $A_{n_{q}+1}=A_{1}$, for all $q \in \mathbb{N}$, then $\lim _{p \rightarrow \infty}\left\|x_{n_{q}}-x^{*}\right\|=0$ and

$$
0=\lim _{q \rightarrow \infty} A_{n_{q}+1} x_{n_{q}}=\lim _{q \rightarrow \infty} A_{1} x_{n_{q}} .
$$

Since $A_{1}$ is $\gamma$-inverse strongly monotone, it is Lipschitz continuous, and thus

$$
A_{1} x^{*}=A_{1}\left(\lim _{q \rightarrow \infty} x_{n_{q}}\right)=\lim _{q \rightarrow \infty} A_{1} x_{n_{q}}=0 .
$$


Hence,

$$
x^{*} \in A_{1}^{-1}(0) .
$$

Continuing this process, we obtain that $x^{*} \in A_{i}^{-1}(0)$, for all $i=1,2, \ldots, N$. Hence,

$$
x^{*} \in \bigcap_{n=1}^{N} A_{n}^{-1}(0)
$$

(V) Next, we prove that $x^{*} \in \bigcap_{m=1}^{M} \operatorname{GMEP}\left(F_{m}, B_{m}, \Phi_{m}\right)$.

Putting $\mathcal{S}_{n}^{m}=K_{r_{m, n}}^{\Gamma_{m}} K_{r_{m-1, n}}^{\Gamma_{m-1}} \cdots K_{r_{2, n}}^{\Gamma_{2}} K_{r_{1, n}}^{\Gamma_{1}}$ for $m \in\{1,2, \ldots, M\}$ and $S_{n}^{0}=I$ for all $n \in \mathbb{N}$. For any $p \in \Omega$, we have

$$
\begin{aligned}
\phi\left(\mathcal{S}_{n}^{m} z_{n}, \mathcal{S}_{n}^{m-1} z_{n}\right) & \leq \phi\left(p, \mathcal{S}_{n}^{m-1} z_{n}\right)-\phi\left(p, \mathcal{S}_{n}^{m} z_{n}\right) \\
& \leq \phi\left(p, z_{n}\right)-\phi\left(p, \mathcal{S}_{n}^{m} z_{n}\right) \\
& \leq \phi\left(p, x_{n}\right)+\xi_{n}-\phi\left(p, \mathcal{S}_{n}^{m} z_{n}\right) \quad(\text { by (3.13) }) \\
& =\phi\left(p, x_{n}\right)+\xi_{n}-\phi\left(p, u_{n}\right) .
\end{aligned}
$$

It follows from (3.22) that $\lim _{n \rightarrow \infty} \phi\left(\mathcal{S}_{n}^{m} z_{n}, \mathcal{S}_{n}^{m-1} z_{n}\right)=0$. Since $E$ is 2-uniformly convex and uniformly smooth Banach space and $\left\{z_{n}\right\}$ is bounded, we have that

$$
\lim _{n \rightarrow \infty}\left\|\mathcal{S}_{n}^{m} z_{n}-\mathcal{S}_{n}^{m-1} z_{n}\right\|=0, \quad m=1,2, \ldots, M
$$

Since $x_{n} \rightarrow x^{*}$ and $u_{n} \rightarrow x^{*}$, now we prove that for each $m=1,2, \ldots, M, S_{n}^{m} z_{n} \rightarrow x^{*}$ as $n \rightarrow \infty$. In fact, if $m=M$, then we have

$$
\lim _{n \rightarrow \infty}\left\|S_{n}^{M} z_{n}-S_{n}^{M-1} z_{n}\right\|=\lim _{n \rightarrow \infty}\left\|u_{n}-S_{n}^{M-1} z_{n}\right\|=0
$$

that is, $S_{n}^{M-1} z_{n} \rightarrow x^{*}$. By induction, the conclusion can be obtained. Since $J$ is norm-to-norm uniformly continuous on bounded subsets of $E$, we get

$$
\lim _{n \rightarrow \infty}\left\|J \mathcal{S}_{n}^{m} z_{n}-J \mathcal{S}_{n}^{m-1} z_{n}\right\|=0
$$

and since $r_{k, n} \in[d, \infty)$ for some $d>0$, we have that

$$
\lim _{n \rightarrow \infty} \frac{\left\|J \mathcal{S}_{n}^{m} z_{n}-J \mathcal{S}_{n}^{m-1} z_{n}\right\|}{r_{m, n}}=0
$$


Next, since $\Gamma_{m}\left(\mathcal{S}_{n}^{m} z_{n}, y\right)+\left(1 / r_{m, n}\right)\left\langle y-\mathcal{S}_{n}^{m} z_{n}, J \mathcal{S}_{n}^{m} z_{n}-J \mathcal{S}_{n}^{m-1} z_{n}\right\rangle \geq 0$, for all $y \in C$, this implies that

$$
\frac{1}{r_{m, n}}\left\langle y-\mathcal{S}_{n}^{m} z_{n}, J \mathcal{S}_{n}^{m} z_{n}-J \mathcal{S}_{n}^{m-1} z_{n}\right\rangle \geq-\Gamma_{m}\left(\mathcal{S}_{n}^{m} z_{n}, y\right) \geq \Gamma_{m}\left(y, \mathcal{S}_{n}^{m} z_{n}\right), \quad \forall y \in C
$$

This implies that

$$
\begin{aligned}
\Gamma_{m}\left(y, \mathcal{S}_{n}^{m} z_{n}\right) & \leq \frac{1}{r_{m, n}}\left\langle y-\mathcal{S}_{n}^{m} z_{n}, J \mathcal{S}_{n}^{m} z_{n}-J \mathcal{S}_{n}^{m-1} z_{n}\right\rangle \\
& \leq\left(M_{1}+\|y\|\right) \frac{\left\|J \mathcal{S}_{n}^{m} z_{n}-J \mathcal{S}_{n}^{m-1} z_{n}\right\|}{r_{m, n}}
\end{aligned}
$$

for some $M_{1} \geq 0$. Since $y \mapsto \Gamma_{m}(x, y)$ is a convex and lower semicontinuous, we obtain from (3.45) and (3.47) that

$$
\Gamma_{m}\left(y, x^{*}\right) \leq \liminf _{n \rightarrow \infty} \Gamma_{m}\left(y, \mathcal{S}_{n}^{m} z_{n}\right) \leq 0, \quad \forall y \in C
$$

For any $t \in(0,1]$ and $y \in C$, then $y_{t}=t y+(1-t) x^{*} \in C$. Since $\Gamma_{m}$ satisfies conditions (A1) and (A4), from (3.48), we have

$$
\begin{aligned}
0 & =\Gamma_{m}\left(y_{t}, y_{t}\right) \leq t \Gamma_{m}\left(y_{t}, y\right)+(1-t) \Gamma_{m}\left(y_{t}, x^{*}\right) \\
& \leq t \Gamma_{m}\left(y_{t}, y\right), \quad \forall m=1,2, \ldots M .
\end{aligned}
$$

Delete $t$, and then let $t \rightarrow 0$, by condition (A3), we have

$$
0 \leq \Gamma_{m}\left(x^{*}, y\right), \quad \forall y \in C, \forall m=1,2, \ldots M,
$$

that is, for each $m=1,2, \ldots, M$, we have

$$
F_{m}\left(x^{*}, y\right)+\left\langle y-x^{*}, B_{m} x^{*}\right\rangle+\Psi_{m}(y)-\Psi_{m}\left(x^{*}\right) \geq 0, \quad \forall y \in C
$$

Therefore, we have that

$$
x^{*} \in \bigcap_{m=1}^{M} \operatorname{GMEP}\left(F_{m}, B_{m}, \Phi_{m}\right)
$$

This completes the proof.

Remark 3.3. (1) Theorem 3.2 not only improves and extends the main results in $[3,6-10]$ but also improves and extends the corresponding results of Chang et al. [1, 15], Wang et al. [16], Su et al. [17], and Kang et al. [18].

(2)It should be pointed out that the results presented in the paper can be used directly to study the existence problems and approximal problems of solutions to optimization 
problems, monotone variational inequality problems, variational inclusion problems, and equilibrium problems in some Banach spaces. For saving space, we will give them in another paper.

\section{Acknowledgment}

The authors would like to express their thanks to the referees for their helpful comments and suggestions.

\section{References}

[1] S.S. Chang, H. W. Lee, and C. K. Chan, "A new hybrid method for solving a generalized equilibrium problem, solving a variational inequality problem and obtaining common fixed points in Banach spaces, with applications," Nonlinear Analysis: Theory, Methods E Applications, vol. 73, no. 7, pp. 2260$2270,2010$.

[2] L. C. Ceng and J. C. Yao, "A hybrid iterative scheme for mixed equilibrium problems and fixed point problems," Journal of Computational and Applied Mathematics, vol. 214, no. 1, pp. 186-201, 2008.

[3] J. F. Tang and S. S. Chang, "Strong convergence theorem for a generalized mixed equilibrium problem and fixed point problem for a family of infinitely nonexpansive mappings in Hilbert spaces," Panamerican American Mathematical Journal, vol. 19, no. 2, pp. 75-86, 2009.

[4] Y. I. Alber, "Metric and generalized projection operators in Banach spaces: properties and applications," in Theory and Applications of Nonlinear Operators of Accretive and Monotone Type, A. G. Kartosator, Ed., vol. 178 of Lecture Notes in Pure and Applied Mathematics, pp. 15-50, Dekker, New York, NY, USA, 1996.

[5] S. Matsushita and W. Takahashi, "A strong convergence theorem for relatively nonexpansive mappings in a Banach space," Journal of Approximation Theory, vol. 134, no. 2, pp. 257-266, 2005.

[6] Y. F. Su, J. Y. Gao, and H. Y. Zhou, "Monotone CQ algorithm of fixed points for weak relatively nonexpansive mappings and applications," Journal of Mathematical Research and Exposition, vol. 28, no. 4, pp. 957-967, 2008.

[7] H. Zhang and Y. F. Su, "Strong convergence of modified hybrid algorithm for quasi- $\phi$-asymptotically nonexpansive mappings," Communications of the Korean Mathematical Society, vol. 24, no. 4, pp. 539$551,2009$.

[8] H. Zegeye and N. Shahzad, "Strong convergence theorems for monotone mappings and relatively weak nonexpansive mappings," Nonlinear Analysis: Theory, Methods \& Applications, vol. 70, no. 7, pp. 2707-2716, 2009.

[9] K. Wattanawitoon and P. Kumam, "Strong convergence theorems by a new hybrid projection algorithm for fixed point problems and equilibrium problems of two relatively quasi- $\phi$-nonexpansive mappings," Nonlinear Analysis: Hybrid Systems, vol. 3, no. 1, pp. 11-20, 2009.

[10] S. S. Zhang, "The generalized mixed equilibrium problem in Banach spaces," Applied Mathematics and Mechanics, vol. 30, no. 9, pp. 1105-1112, 2009.

[11] H. K. Xu, "Inequalities in Banach spaces with applications," Nonlinear Analysis: Theory, Methods $\mathcal{E}$ Applications, vol. 16, no. 12, pp. 1127-1138, 1991.

[12] S. Kamimura and W. Takahashi, "Strong convergence of a proximal-type algorithm in a Banach space," SIAM Journal on Optimization, vol. 13, no. 3, pp. 938-945, 2003.

[13] E. Blum and W. Oettli, "From optimization and variational inequalities to equilibrium problems," The Mathematics Student, vol. 63, no. 1-4, pp. 123-145, 1994.

[14] W. Takahashi and K. Zembayashi, "Strong and weak convergence theorems for equilibrium problems and relatively nonexpansive mappings in Banach spaces," Nonlinear Analysis: Theory, Methods $\mathcal{E}$ Applications, vol. 70, no. 1, pp. 45-57, 2009.

[15] S. S. Chang, C. K. Chan, and H. W. Joseph Lee, "Modified block iterative algorithm for quasi$\phi$-asymptotically nonexpansive mappings and equilibrium problem in banach spaces," Applied Mathematics and Computation, vol. 217, no. 18, pp. 7520-7530, 2011.

[16] Z. M. Wang, Y. F. Su, D. X. Wang, and Y. C. Dong, “A modified halpern-type iteration algorithm for a family of hemi-relatively nonexpansive mappings and systems of equilibrium problems in Banach spaces," Journal of Computational and Applied Mathematics, vol. 235, no. 8, pp. 2364-2371, 2011. 
[17] Y. F. Su, H. K. Xu, and X. Zhang, "Strong convergence theorems for two countable families of weak relatively nonexpansive mappings and applications," Nonlinear Analysis: Theory, Methods $\mathcal{E}$ Applications, vol. 73, no. 12, pp. 3890-3906, 2010.

[18] J. Kang, Y. F. Su, and X. Zhang, "Hybrid algorithm for fixed points of weak relatively nonexpansive mappings and applications," Nonlinear Analysis: Theory, Methods \& Applications, vol. 4, no. 4, pp. 755$765,2010$. 


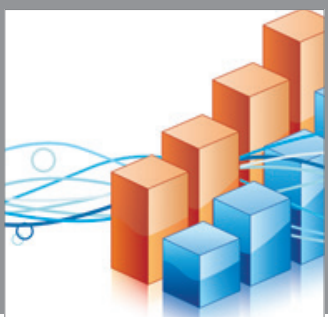

Advances in

Operations Research

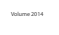

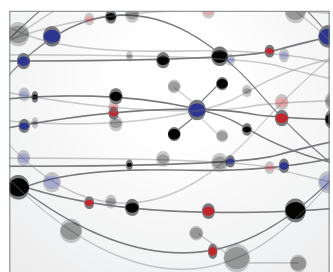

\section{The Scientific} World Journal
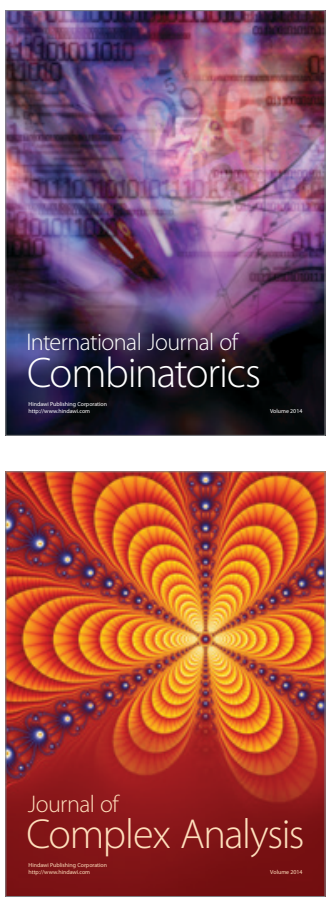

International Journal of

Mathematics and

Mathematical

Sciences
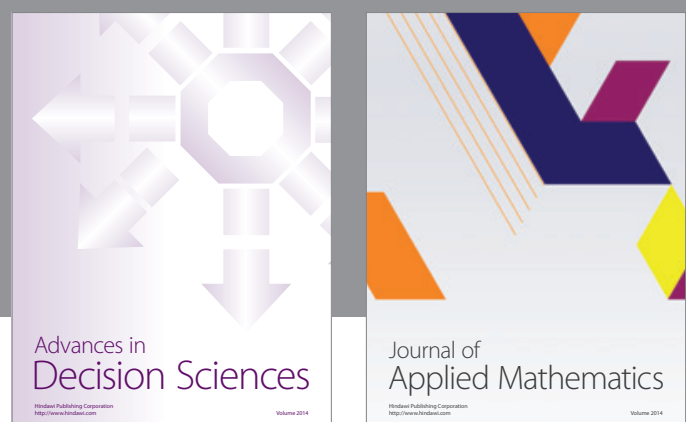

Journal of

Applied Mathematics
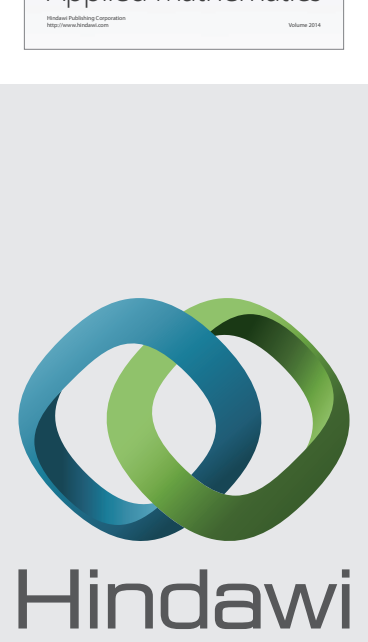

Submit your manuscripts at http://www.hindawi.com
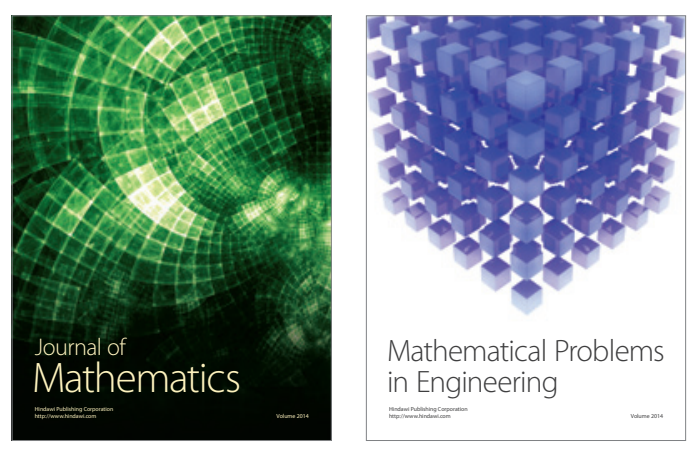

Mathematical Problems in Engineering
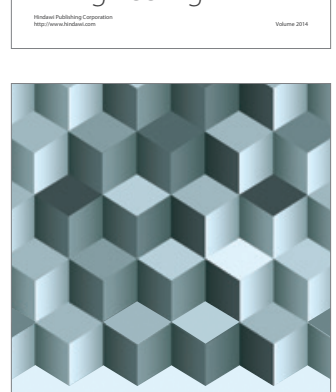

Journal of

Function Spaces
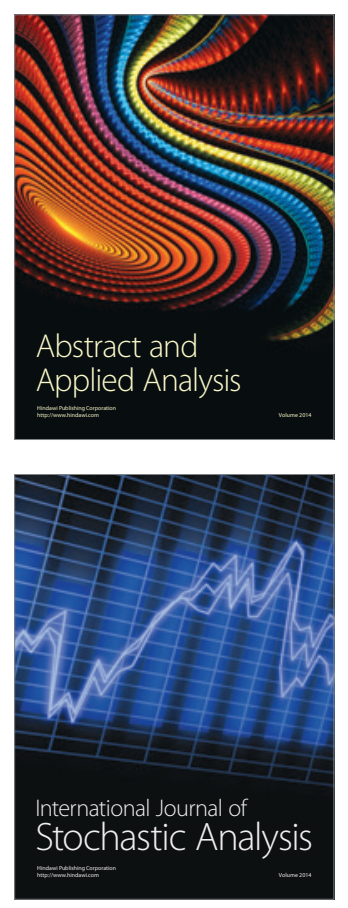

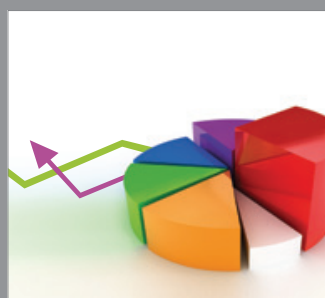

ournal of

Probability and Statistics

Promensencen
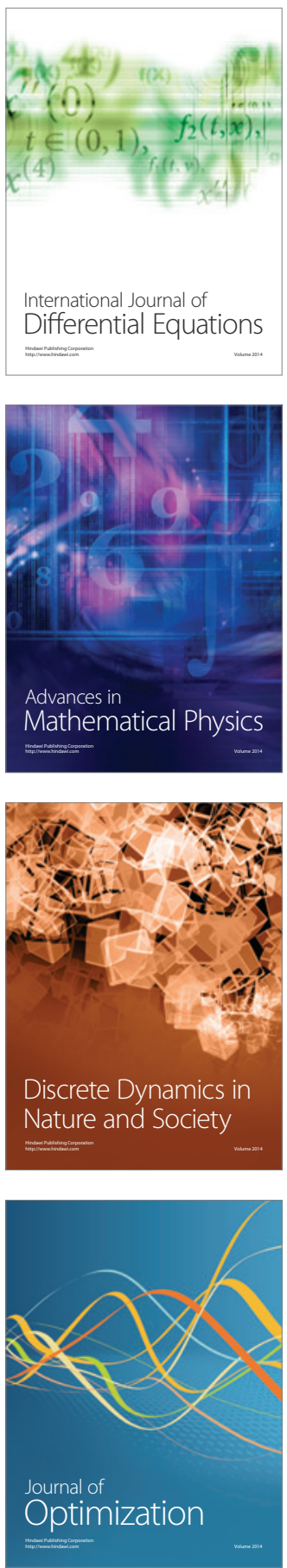